\title{
Metabolic activity of breast cancer metastatic lesions on positron emission tomography/computed tomography: comparison with histological and biological characteristics of primary tumor
}

\author{
D. SOBIC SARANOVIC ${ }^{1,2}$, M. STOJILJKOVIC ${ }^{1, *}$, S. SUSNJAR ${ }^{3}$, S. ODALOVIC ${ }^{1,2}$, V. ARTIKO ${ }^{1,2}$, S. PAVLOVIC $^{1,2}$, I. GROZDIC-MILOJEVIC ${ }^{2}$, \\ V. OBRADOVIC 1,2
}

${ }^{1}$ Faculty of Medicine, University of Belgrade, Belgrade, Serbia; ${ }^{2}$ Center of Nuclear Medicine, Clinical Center of Serbia, Belgrade, Serbia; ${ }^{3}$ Institute of Oncology and Radiology of Serbia, Belgrade, Serbia

${ }^{*}$ Correspondence: milica_stoji@yahoo.com

Received August 13, 2015 / Accepted October 13, 2015

\begin{abstract}
Higher intensity of FDG uptake on PET/CT in primary tumor is seen in patients with IDC compared to ILC, also in high grade tumours, tumours with negative ER and higher Ki67 values, while data are inconsistent in case of relation between primary tumor's PgR and HER2 expression with its metabolic activity levels. On account of the lack of studies that include research of breast cancer metastatic lesion metabolism level and its relation to tumor histology and biology, our goal was to investigate the association of metastatic lesions' glucose metabolism level on PET/CT with different histological and biological characteristics of primary tumor. In a total number of $\mathrm{N}=100$ patients, highest SUVmax values for each patient were used in testing difference between metastatic metabolic activity in patients with different tumor histology, grade, ER, PgR and HER2 status, subtype, as well in testing relation of Ki67 index to metastasis' metabolism level. In testing difference between histological types of breast cancer, SUVmax values were also compared separately for each specific anatomical site (regional and distant lymph nodes, bones and liver). No difference was found regarding metastatic SUVmax values in patients with primary IDC ( $n=55$, median SUVmax 9.70) and ILC $(n=34$, median SUVmax 7.20) independently of anatomic site, and for each of analysed sites separately. No difference was found as well between SUVmax detected in metastasis in patients with different grade (grade II: $\mathrm{n}=58$, median SUVmax 7.70; grade III: $\mathrm{n}=12$, median SUVmax 10.20), ER (59 positive, median SUVmax 8.50; 22 negative, median SUVmax 8.05), PgR (55 positive, median SUVmax 8.50; 23 negative, median SUVmax 7.80), and HER2 (14 positive, median SUVmax 6.84; 51 negative, median SUVmax 8.63) expression in primary tumor, and between patients with different tumor subtype. Ki67 was also not associated with tumor metastatic SUVmax values $(n=11, r$ $=-0.21, \mathrm{p}=0.53$ ). We conclude that there is no association of primary breast cancer histological type, grade, ER, PgR, HER2 and Ki67 expression with metabolic activity in metastasis detected on PET/CT.
\end{abstract}

Key words: breast cancer, positron emission tomography, metastasis, metabolism,SUVmax

Breast cancer (BC) represents the most frequent malignancy and main cause of cancer-related deaths in women in the world [1]. Most common histological types of BC are invasive ductal carcinoma (IDC) and invasive lobular carcinoma

Abbreviations: 18F-FDG - fluorodeoxyglucose labelled with radioactive Fluor 18F; CAIX - carbonic anhydrase IX; CT - computed tomography; ER - estrogen receptors; Glut1 - facilitated glucose transporter type 1; HER2 human epidermal growth factor receptor 2; IDC - invasive ductal carcinoma; IHC - immunohistochemical; ILC - invasive lobular carcinoma; MCT4 monocarboxylate transporter4; PET - positron emission tomography; PgR - progesterone receptors; SUVmax - maximal standardized uptake value
(ILC). Beside IDC and ILC, other common histological types of BC are mucinous, medullar, tubular, comedo, inflammatory and papillary, which together represents approximately $10 \%$ of all diagnosed breast cancers [2]. Besides traditional histopathological diagnosis of breast cancer, which included histological type and tumor grade, the intrinsic subtypes of BC have been recognized earlier $[3,4]$. Surrogate markers determined by immunohistochemical (IHC) measurements of estrogen receptors (ER), progesterone receptors (PgR), Ki67 and HER2 are used to define BC subtypes: luminal Alike, luminal B-like, HER2 positive and triple negative (TN) 
$\mathrm{BCs}$, and their role as prognostic and predictive factors is well known [5].

Role of positron emission tomography/computed tomography (PET/CT) with 18F-fluorodeoxyglucose (FDG) in staging and restaging breast cancer patients is constantly increasing, along with number of evidence regarding its impact in therapy selection and management of these patients [6], with particular importance of PET/CT in detection of distant metastasis [7]. FDG accumulation in primary BC is mainly Glut1-mediated and correlates with Glut1 and hexokinase expression, but also with microvascular density, number of viable tumor cells, cell proliferation rate, lymphocyte count and hypoxia-inducible factor $1 \alpha($ HIF-1 $\alpha)$ expression $[8,9]$. Higher FDG uptake in primary tumor is seen in ductal compared with lobular type [10], whereas mixed (ductal + lobular) primary tumor also shows lower glucose metabolism level in comparison with IDC [11]. There are numerous studies that investigate relation of FDG uptake level with tumor histological grade and ER, PgR, HER2 and Ki67 expression. They show that higher SUVmax values are detected in tumors with higher grade, tumors with negative ER and with higher Ki67 index, while the results regarding relation of HER2 and PgR to metabolic activity level are equivocal $[10,11,12,13]$. Also, primary tumor SUVmax detected on FDG PET/CT has been proven to have prognostic role in breast cancer patients [14]. However, most of the authors are investigating metabolism level in primary tumor. More recently, studies that include investigation of SUVmax values in breast cancer metastasis have appeared, showing that bone metastasis metabolism level can have prognostic value in patient with disseminated disease, while FDG uptake level in liver, lungs and lymph nodes lesions does not appear to have prognostic significance $[15,16]$.

Lack of the studies that include research of breast cancer metastatic lesion metabolism level and its relation to tumor histology and biology indicates the need of further investigation and evaluation of this domain. Therefore our study's main goal was to determine whether there is connection of metabolic activity of breast cancer metastasis on FDG PET/CT with histological type of primary tumor. Additional goals were to determine relation of primary tumor subtype, histological grade, hormone receptor and HER2 expression and Ki67 index to secondary lesions metabolism level detected on PET/CT.

\section{Patients and methods}

This study was conducted in National PET centre, Centre for Nuclear medicine, Clinical centre of Serbia. Study included all consecutive patients diagnosed with breast cancer, who underwent PET/CT examination from October 2009 until September 2014, and who fulfilled inclusion criteria: 1) previously histologically proven breast cancer, 2 ) available data concerning breast cancer histological type, 3) metastatic lesions detected on PET/CT. Exclusion criteria were: 1) previously proven presence of other malignant tumor, 2) end of chemotherapy less than a month ago. Data concern- ing clinical and pathological parameters, which included tumor histological type and grade, ER, PgR, HER2 and Ki67 expression, and previous specific oncologic therapy, were taken from medical documentation that patients enclose for PET centre archive. Estrogen and progesterone receptors were interpreted as positive when: Allred score was $\geq 3$, staining was present in $\geq 1 \%$ cells or $H$ score was $>1[17,18]$, or $\geq 10 \mathrm{fmol} / \mathrm{mg}$ (ER) and $\geq 20 \mathrm{fmol} / \mathrm{mg}$ (PgR) of protein was detected [19], depending on type of test. HER2 was considered positive in case of score $3+$ obtained by IHC analysis, or if gene amplification was detected by chromogenic in situ hybridisation (when IHC score was 2+). Results of Ki67 IHC testing were expressed as percentage of cells that bind antibody (low Ki67 index $<15 \%$, high Ki67 index $\geq 40 \%$ ). Patients with known ER, PgR and HER2 were classified into following subgroups: a) luminal subtype (ER+ and/or PgR+/HER2-neg), b) luminal HER2-pos (ER+ and/or PgR+/ HER2-pos), c) triple-negative (ER-/PgR-/HER2-neg), and d) non-luminal HER2-pos (ER-/PgR-/HER2-pos).

PET/CT examination was done on hybrid PET/CT scanner Biograph True64, Siemens medical solutions USA Inc. Patients were given an average dose of $5.5 \mathrm{MBq} / \mathrm{kg}$ body weight $18 \mathrm{~F}$ FDG intravenously, after starving period of at least 6 hours, and with blood glucose level $<11 \mathrm{mmol} / \mathrm{l}$. After resting period (60-90 minutes after FDG administration), patients underwent low-dose CT $(120 \mathrm{kV}, 40 \mathrm{mAs}$, slice thickness $5 \mathrm{~mm}$, pitch 1.5 , rotation time $0.5 \mathrm{~s}$ ) without contrast, for topographic localisation and attenuation correction. That was followed by PET acquisition (standard Whole body procedure) of region from the base of scull to the mid-thighs ( 3 minutes per bed, 6-7 beds per examinee) in three-dimensional mode.

Obtained PET/CT data were interpreted on Syngo Multimodality Workplace VE31A (Syngo 2008B, Siemens, Medical systems, Erlangen, Germany). Image interpretation was done by nuclear medicine specialist and, after elimination of physiologic and inflammation/infection caused FDG avid areas, other lesions with increased FDG uptake were interpreted as presence of malignancy. Only in a number of patients histopathological confirmation of detected metastatic lesions was available, while clinical follow-up was used as a confirmation of metastatic disease in others. For assessment of glucose metabolism level in metastasis, SUVmax was used, that is singular voxel within region of interest with maximal standard uptake value, calculated as: activity in tissue (count/pixel/s) multiplied by calibration factor and divided by dose applied $(\mathrm{MBq} / \mathrm{kg}$ of body weight). SUVmax was determined for FDG avid lesions in skeletal system, liver, lungs and regional (ipsilateral axillar, supra and infraclavicular and along internal thoracic artery) and distant lymph nodes. Highest SUVmax values for each patient were used in testing difference between metastatic metabolic activity in patients with different tumor histology, grade, ER, PgR and HER2 status, tumor subtype, as well in testing relation of Ki67 index to metastasis' metabolism level. In testing difference between histological types of breast cancer, SUVmax values were also compared separately for each 
specific anatomical site (regional and distant lymph nodes, bones and liver).

Statistical analysis, which included descriptive and analytical methods, was done in program R 3.0.2. Chi-squared test was used to test whether there is difference in frequency of IDC and ILC metastasis on different anatomical sites. In analysing the relation of metastatic SUVmax values to histological type (IDC and ILC), grade (grades II and III), ER, PgR, and HER2 expression (positive vs. negative), tumor subtype, chemotherapy and endocrine therapy, Mann-Whitney $U$ test and Kruskal-Wallis rank sum test were used. Correlation between Ki67 index and SUVmax values was analysed with Spearman's rang correlation coefficient. P-values of $\leq 0.05$ were considered statistically significant.

\section{Results}

Our study included 100 patients (1 male), average age $55 \pm 13$ years, who had breast cancer metastatic lesions seen on PET/CT. Total number of PET/CT examinations was 128, with 80 patients who underwent PET/CT scan once, while 14, 4 and 2 patients were examined on PET/CT two, three or four times, respectively. All PET/CT examinations were done for the purpose of patients' restaging after already previously treated breast cancer (surgery and/or chemotherapy and/or radiation therapy), and with particular indications: therapy efficiency assessment (in 51 PET/CT examination), pathological or equivocal findings on other imaging modalities $(n=44)$, increased level of tumor markers $(n=23)$ and routine check-up $(\mathrm{n}=10)$. Tumor histology data were available for each patient. Only in a number of patients, other histological and biological data were known: tumor grade in 74 patients, ER status in 81 and PgR status in 78 patients, HER2 in 65, and Ki67 in 11 patients. The most frequent histological type was invasive ductal carcinoma, which was detected in 55 patients, whereas 34 patients had invasive lobular carcinoma, which was the second most frequent type. Other detected histological types (in the remaining $\mathrm{n}=11$ patients) were: mucinous, mixed and medullar. Demographic and other clinical characteristics of patients, as well as tumor characteristics, are given in Tables 1 and 2.

Most common sites of PET/CT detected distant metastases in all patients were: lymph nodes, bones, lungs and liver. Presence of malignant disease in regional lymph nodes was seen in 28 patients. Other sites of PET/CT detected metastases were: pleura, soft tissues, uterus and adnexa, adrenal glands, peritoneum. When it comes to different histological types, most frequent sites of metastases in patients with IDC were distant lymph nodes, skeletal system and lung parenchyma (Fig. 1), while bones, distant lymph nodes and liver were the most frequent sites of metastasis in ILC patients (Fig. 2). Distribution of FDG avid lesions according to histological type of $\mathrm{BC}$ is given in Table 3. There was no significant difference in frequency of metastases in bones, liver and distant or regional lymph nodes between patients with IDC and ILC. Only lung
Table 1. Demographic and clinical characteristics of patients

\begin{tabular}{lc}
\hline & $\begin{array}{c}\text { Total number of patients } \\
\text { N=100 }\end{array}$ \\
\hline $\begin{array}{l}\text { Gender } \\
\text { female }\end{array}$ & 99 \\
male & 1 \\
Previous surgery & 55 \\
radical mastectomy & 12 \\
subcutaneous mastectomy & 20 \\
quadrantectomy & 5 \\
partial resection & 8 \\
none (biopsy only) & \\
Previous radiation therapy & 65 \\
$\quad$ yes & 35 \\
no & \\
Previous chemotherapy & 89 \\
yes & 11 \\
no & \\
Hormonotherapy & 62 \\
yes* & 28 \\
no & 10 \\
unknown & ${ }^{*}$ patients who are or who were treated with LHRH analogues/ antiestrogens/ \\
aromatase inhibitors/ progestogens &
\end{tabular}

Table 2. Pathological and biological characteristics of tumor

\begin{tabular}{lc}
\hline Histological type & $\mathrm{N}=100$ \\
IDC & 55 \\
ILC & 34 \\
Mixed & 6 \\
Mucinous & 3 \\
Medullar & 2 \\
Tumor grade & $\mathrm{n}=74$ \\
I & 4 \\
II & 58 \\
III & 12 \\
Estrogen receptors & $\mathrm{n}=81$ \\
Positive & 59 \\
Negative & 22 \\
Progesterone receptors & $\mathrm{n}=78$ \\
Positive & 55 \\
Negative & 23 \\
HER2 & $\mathrm{n}=65$ \\
Positive & 14 \\
Negative & 51 \\
\hline
\end{tabular}

metastases were statistically more frequent in patients with ductal type than in ILC patients (Table 4).

Median values of SUVmax in FDG avid lesions in patients with ductal and lobular BC are given in Table 5. Statistically significant difference was not found between IDC and ILC patients' highest SUVmax values on each anatomical site separately (regional and distant lymph nodes, bones and liver), as well independently of site (Table 5). 


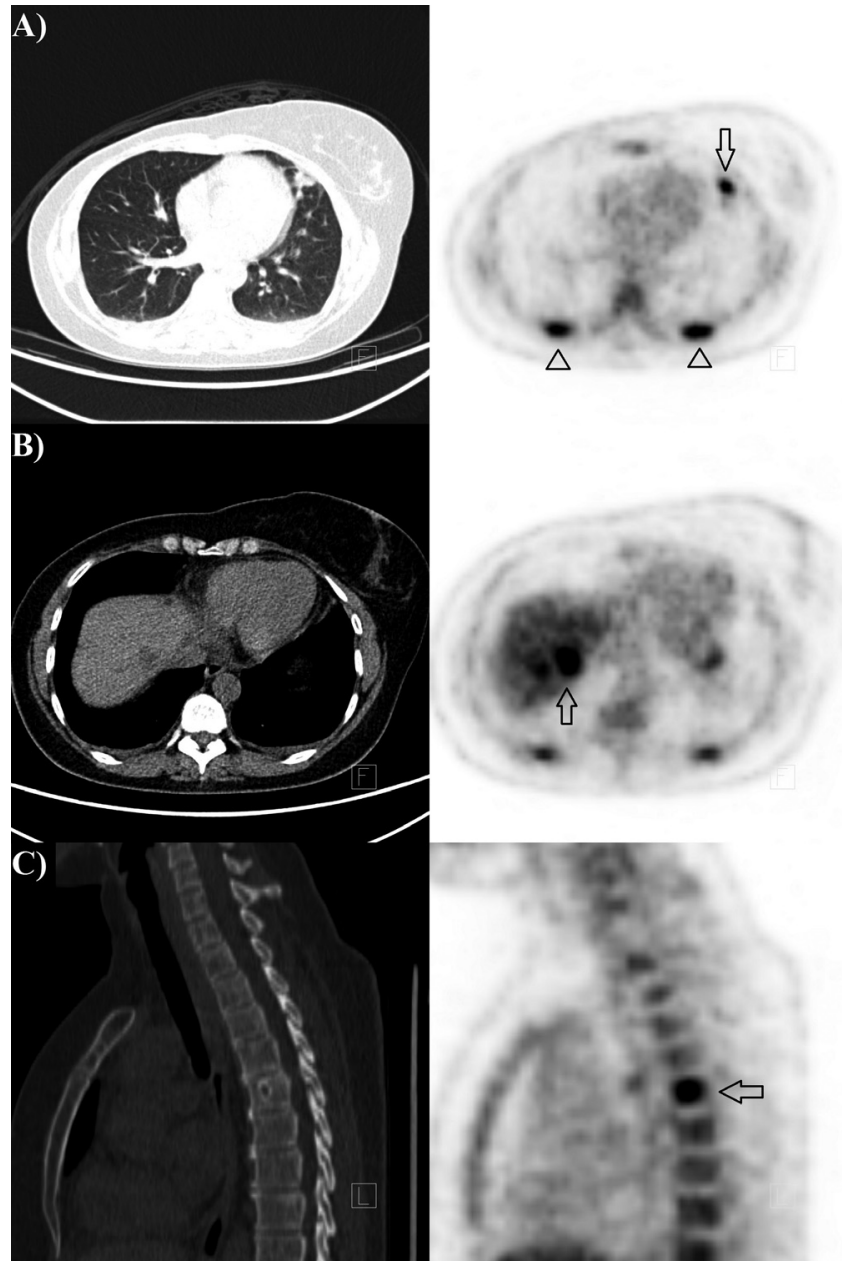

Figure 1. Patient (41y, female) with invasive ductal carcinoma of breast. Low dose CT and PET: A) FDG avid lesions in left lung (arrow) and pleura bilateral (arrowheads), B) focal zone of increased FDG uptake in liver (arrow), C) metastatic lesion in thoracic vertebra (arrow).
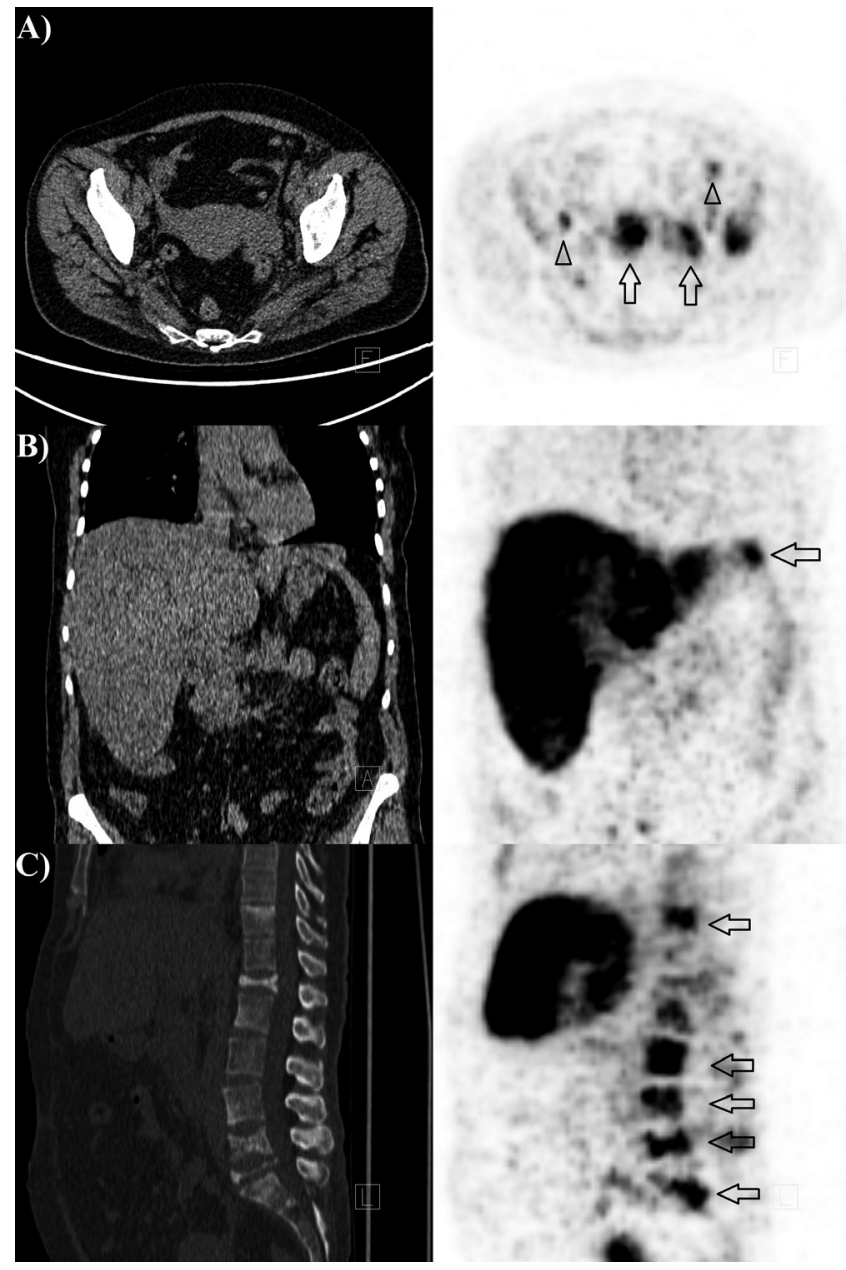

Figure 2. Patient (51y, female) with invasive lobular carcinoma of breast. Low dose CT and PET: A) FDG avid lesions in uterus and left ovary (arrows) and in lymph nodes (arrowheads), B) diffuse increased FDG uptake in liver and focal zone of increased FDG uptake in peritoneum (arrow), C) metastatic lesions in vertebrae and sacrum (arrows).

Table 3. Prevalence of metastases by anatomical sites in patients with different histological types of breast cancer

\begin{tabular}{|c|c|c|c|c|c|c|c|c|}
\hline & \multirow{2}{*}{$\begin{array}{l}\text { All patients }(\mathrm{N}=100) \\
\mathrm{N}\end{array}$} & \multicolumn{2}{|c|}{ IDC $(n=55)$} & \multicolumn{2}{|c|}{$\operatorname{ILC}(\mathrm{n}=34)$} & \multirow{2}{*}{$\begin{array}{c}\begin{array}{c}\text { Mixed } \\
(\mathrm{n}=6)\end{array} \\
\mathrm{n}\end{array}$} & \multirow{2}{*}{$\begin{array}{c}\text { Mucinous } \\
(\mathrm{n}=3)\end{array}$} & \multirow{2}{*}{$\begin{array}{c}\begin{array}{c}\text { Medullar } \\
(\mathrm{n}=2)\end{array} \\
\mathrm{n}\end{array}$} \\
\hline & & $\mathrm{n}$ & $(\%)$ & $\mathrm{n}$ & $(\%)$ & & & \\
\hline Distant lymph nodes & 62 & 36 & $(65)$ & 21 & $(62)$ & 2 & 1 & 2 \\
\hline Skeletal system & 59 & 30 & $(55)$ & 23 & $(68)$ & 5 & & 1 \\
\hline Lung parenchyma & 29 & 20 & $(36)$ & 4 & $(12)$ & 3 & 2 & \\
\hline Liver & 27 & 17 & $(31)$ & 9 & $(26)$ & 1 & & \\
\hline Pleura & 5 & 4 & $(7)$ & & & & & \\
\hline Soft tissues* & 5 & 4 & $(7)$ & & & 1 & & \\
\hline Uterus and adnexa & 3 & & & 2 & (6) & 1 & & \\
\hline Adrenal glands & 2 & 1 & $(2)$ & & & & 1 & \\
\hline Peritoneum & 1 & & & 1 & (3) & & & \\
\hline Regional lymph nodes & 28 & 19 & (35) & 8 & $(24)$ & & 1 & \\
\hline
\end{tabular}

IDC-invasive ductal carcinoma, ILC-invasive lobular carcinoma, ${ }^{*}-$ subcutaneous tissue and skeletal muscles 
Patients with different tumor grade and with different ER, $\mathrm{PgR}$ and HER2 status did not significantly differ according to metastatic lesions' SUVmax values (Table 6). Patients with grade I tumor were excluded from statistical analysis due to their low count $(\mathrm{n}=4)$. In 11 examinees Ki67 index was known. By testing the correlation of Ki67 index with SUVmax values in these patients statistical significance was not found $\left(\mathrm{r}_{\mathrm{s}}=\right.$ $-0.21, \mathrm{p}=0.53)$, Fig 3 .

Table 4. Difference in distribution of metastasis in patients with IDC and ILC

\begin{tabular}{lccccc}
\hline & \multicolumn{2}{c}{ IDC $(\mathrm{n}=55)$} & \multicolumn{2}{c}{ ILC $(\mathrm{n}=34)$} & \multirow{2}{*}{ P value $^{*}$} \\
\cline { 2 - 5 } & $\mathrm{n}$ & $\%$ & $\mathrm{n}$ & $\%$ & \\
\hline Regional lymph nodes & 19 & 35 & 8 & 24 & 0.27 \\
\hline Distant lymph nodes & 36 & 65 & 21 & 62 & 0.72 \\
Skeletal system & 30 & 55 & 23 & 68 & 0.93 \\
Liver & 17 & 31 & 9 & 26 & 0.65 \\
Lung parenchyma & 20 & 36 & 4 & 12 & $\mathbf{0 . 0 1}$ \\
\hline
\end{tabular}

IDC-invasive ductal carcinoma, ILC-invasive lobular carcinoma, ${ }^{*}-\mathrm{Chi}-$ squared test, bold-p value $\leq 0.05$

Table 5. SUVmax values in metastatic lesions in IDC and ILC patients by anatomical sites

\begin{tabular}{lccccc}
\hline & \multicolumn{2}{c}{ IDC (SUVmax) } & \multicolumn{2}{c}{ ILC (SUVmax) } & P \\
\cline { 2 - 5 } & median & range & median & range & value $^{*}$ \\
\hline Regional lymph nodes & 5.03 & $1.50-15.30$ & 4.71 & $2.30-6.96$ & 0.79 \\
\hline Distant lymph nodes & 7.56 & $3.30-24.51$ & 6.50 & $3.28-18.10$ & 0.42 \\
Skeletal system & 7.90 & $2.35-22.23$ & 7.46 & $3.17-20.39$ & 0.51 \\
Liver & 8.80 & $4.60-32.10$ & 11.60 & $3.50-17.78$ & 0.45 \\
\hline All sites & 9.70 & $2.35-32.10$ & 7.20 & $3.17-20.39$ & 0.22 \\
\hline
\end{tabular}

SUVmax-maximal standardized uptake value, IDC-invasive ductal carcinoma, ILC-invasive lobular carcinoma, * - Mann-Whitney U test

Table 6. SUVmax values of metastatic lesions by primary tumor grade and ER, PgR and HER2 status

\begin{tabular}{|c|c|c|c|c|}
\hline $\begin{array}{l}\text { Primary tumor } \\
\text { characteristics }\end{array}$ & & $\begin{array}{c}\text { Number of } \\
\text { patients }\end{array}$ & $\begin{array}{c}\text { SUVmax } \dagger: \\
\text { median (range) }\end{array}$ & P value ${ }^{*}$ \\
\hline \multirow{2}{*}{ Histological grade } & II & 58 & $7.70(2.35-20.39)$ & \multirow[t]{2}{*}{0.48} \\
\hline & III & 12 & $10.20(3.70-22.23)$ & \\
\hline \multirow{2}{*}{ ER } & + & 59 & $8.50(2.35-32.10)$ & \multirow[t]{2}{*}{0.97} \\
\hline & - & 22 & $8.05(3.30-29.67)$ & \\
\hline \multirow{2}{*}{ PgR } & + & 55 & $8.50(2.35-29.67)$ & \multirow[t]{2}{*}{0.87} \\
\hline & - & 23 & $7.80(3.30-32.10)$ & \\
\hline \multirow{2}{*}{ HER2 } & pos & 14 & $6.84(3.30-22.23)$ & \multirow[t]{2}{*}{0.28} \\
\hline & neg & 51 & $8.63(2.35-32.10)$ & \\
\hline
\end{tabular}

SUVmax-maximal standardized uptake value, ER-estrogen receptors, PgR progesterone receptors, $\dagger-$ highest SUVmax value for each patient independently of anatomical site, ${ }^{*}$ - Mann-Whitney U test

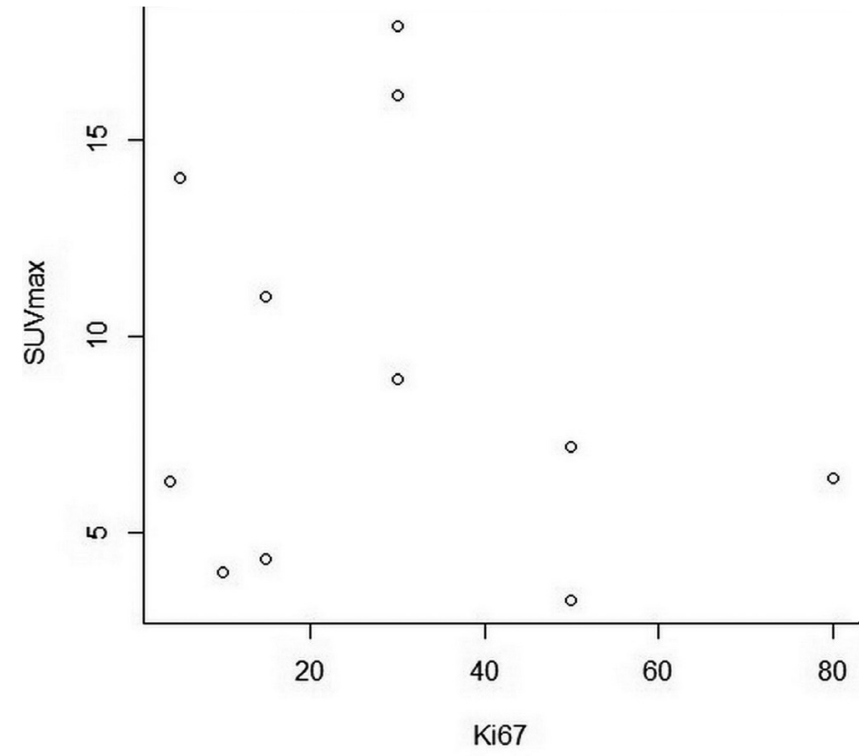

Figure 3. Scatter plot of Ki67 index (\%) and metastatic SUVmax values, $\mathrm{n}=11$.

ER, PgR and HER2 was determined in 65/100 patients and Ki67 in only 11/100, which precluded the precise determination of BC subtypes in our patients. However, these 65 patients were classified into following subgroups: a) luminal subtype (ER+ and/or PgR+/HER2-neg) 41 patients; b) luminal HER2-pos (ER+ and/or PgR+/HER2-pos) 10 patients; c) triple-negative (ER-/PgR-/HER2-neg) 10 patients; and d) non-luminal HER2-pos (ER-/PgR-/HER2-pos) 4 patients. There was no significant difference in SUVmax among them (Table 7).

Regarding association of chemotherapy or endocrine therapy with tumor metabolism on PET/CT, no difference was found between SUVmax values detected in secondary lesions in patients with and without previous chemotherapy treatment $(\mathrm{p}=0.46)$, as well between patients with ongoing, completed or without previous endocrine therapy $(\mathrm{p}=0.23)$.

Our sample included one male patient. He had ductal type of carcinoma, with ER and PgR negative, HER2 posi-

Table 7. SUVmax values of metastatic lesions by primary tumor subtype

\begin{tabular}{lccc}
\hline Primary tumor subtype & $\begin{array}{c}\text { Number of } \\
\text { patients }\end{array}$ & $\begin{array}{c}\text { SUVmax } \\
\text { median (range) }\end{array}$ & P value $^{*}$ \\
\hline ER+ and/or PgR+/HER2-neg & 41 & $8.63(2.35-32.10)$ & 0.81 \\
ER+ and/or PgR+/HER2-pos & 10 & $7.69(3.57-22.23)$ & \\
ER-/PgR-/HER2-neg & 10 & $8.85(5.50-15.30)$ & \\
ER-/PgR-/HER2-pos ${ }^{*}$ & 4 & $6.39(3.30-12.60)$ & \\
\hline
\end{tabular}

SUVmax-maximal standardized uptake value, ER-estrogen receptors, PgR progesterone receptors, $\uparrow-$ highest SUVmax value for each patient independently of anatomical site, ${ }^{*}$ - Kruskal-Wallis rank sum test, $\ddagger-$ excluded from statistical analysis due to small sample size 
tive, and Ki67 expressed in 50\% of cells. He had FDG avid lesions in lungs (SUVmax 3.3) and skeletal system (SUV$\max 3.2)$.

\section{Discussion}

This study examined the association of metastatic lesions' glucose metabolism level on PET/CT with different histological and biological characteristics of primary tumor, mostly in IDC and ILC. The overall results provided evidence that glucose metabolism level in breast cancer metastasis is not associated with primary tumor histological type with possible implication of cell metabolism differences between primary and metastatic tumor. In addition, metabolic activity in breast cancer metastases is not connected with primary tumor characteristics such as histological grade, ER, PgR and HER2 status and Ki67 index, with explanation of possible further tumor dedifferentiation during metastasing.

Among our patients, the most frequent $\mathrm{BC}$ histological type was invasive ductal carcinoma, followed by ILC, which is in agreement with the literature data; although we found the prevalence of ILC (34\%) to be somewhat higher compared to previous studies results $(5-15 \%)[2,20]$.

In all patients, independently of tumor histological type, most common sites of distant metastases were lymph nodes, followed by skeletal system, lungs and liver, which agrees with the results of Morris et al [16].Presence of malignancy in gynaecological organs and peritoneum was detected only in patients with ILC but not in IDC patients, while secondary lesions in lung parenchyma were significantly more frequent in IDC than in patients with lobular type, which is all in concordance with previous studies [21,22].

It is known from before that the different metabolic processes are present in cells of different tumor types [23]. With regard to breast cancer, ILC and IDC show different levels of expression of glucose metabolism-related proteins, such as Glut1, hexokinase II, carbonic anhydrase IX (CAIX) and monocarboxylic transporter 4 (MCT4). IDC is characterised by higher expression of glycolysis in tumor cells, as well as in stromal cells, while ILC is more often non-glycolytic type, and generates energy primarily through mitochondrial oxidative phosphorylation. IDC, besides glycolytic phenotype, shows also glutaminolysis and serine/glycine metabolic phenotype [24]. Also, proliferative activity of primary tumor is lower in lobular than in ductal histological type $[25,26]$. Since tumor FDG accumulation positively correlates with cell proliferation activity and the expression of glucose metabolism-related proteins, it could explain higher FDG uptake in primary breast cancer in patients with IDC compared to ILC patients.

Our results indicate that there is no difference between FDG uptake level in secondary lesions in patients with IDC compared to ILC patients, both in regional (lymph nodes) and distant (lymph nodes, bones, liver) metastases. Deandreis et al. showed also that SUVmax values detected in metastatic lesions (independently of anatomical site) in patient with metastatic thyroid carcinoma were not associated with primary tumor histological type - papillary, follicular or poorly differentiated [27], while, regarding primary thyroid carcinoma FDG uptake, higher FDG accumulation is seen in anaplastic compared to differentiated carcinomas [28] and in papillary than in follicular types [29]. Perhaps the absence of difference in metastasis radiotracer uptake intensity among different $\mathrm{BC}$ histological types could be the consequence of cell metabolism differences between primary and metastatic tumor. BC metastatic cells, found in regional lymph nodes, show different metabolism than primary tumor cells [30]. It has also been shown that the hexokinase activity is considerably higher in metastases compared to primary tumor, indicating the connection of higher glycolytic activity with tumor progression [31,32]. With regard to difference between BC metastatic lesions on different anatomical sites, proteins involved in glycolysis (Glut1, hexokinase II, CAIX and MCT4) show higher level of expression in brain and lung lesions, with lower expression in liver and bones, whereby CAIX and Glut1 positivity in bone metastases and CAIX positivity in lungs is associated with shorter overall survival [33].

Histological tumor grade is used to express the tumor tissue differentiation, i.e. the degree of malignancy. A number of studies show association between primary tumor histological grade and its metabolic activity on FDG PET/CT, which is explained by higher expression of Glut1 and hexokinase seen in poorly differentiated tumors [34]. Our results suggest that there is no difference in glucose metabolism level seen in metastases of breast cancer with different primary tumor grade, which could be the consequence of further tumor dedifferentiation occurring during metastasing.

Although many authors found significantly higher SUVmax values of primary breast cancer in patients with negative estrogen receptors than in ER positive patients, we did not find difference between ER negative and ER positive patients regarding SUVmax detected in metastasis. In respect of PgR expression, and its association with primary tumor glucose metabolism, some of the authors stated that PgR negative tumors could have higher metabolism level, while others found no connection between SUVmax and PgR status. We also did not detect difference between $\mathrm{PgR}$ positive and negative patients by comparing their metastatic SUVmax values $[10,11$, $12,13]$. However, the results of previous studies show that ER and $\mathrm{PgR}$ concentration in regional and distant breast cancer metastases can differ from those in primary tumor, and perhaps that may be the reason of different metabolic behaviour of secondary lesions compared to primary tumor, and could explain our results [35].

While some studies showed that SUVmax could be associated with primary tumor HER2 expression, in terms of higher SUVmax values in HER2 positive patients $[11,36]$, not all of the authors managed to prove the existence of relation HER2 and glucose metabolism level on FDG PET $[12,37]$. We also did not detect the association of HER2 status and metabolic 
activity in metastases in our patients. The absence of relationship between HER2 overexpression and FDG uptake is difficult to explain because it has been proven that HER2 promotes glycolysis in breast cancer cells [38], while, on the other hand, it is known that HER2 expression in primary tumor and its metastasis could vary to a large degree [35], which could be in favour of the results we obtained.

In contrary to prior studies, which have proved positive correlation of Ki67 index and primary tumor FDG accumulation, we found no such connection in case of SUVmax value in metastatic lesions and its relation to primary tumor Ki67 expression, which may be the effect of small sample size $(\mathrm{n}=11)$, but also could be explained with the fact that Ki67 values may differ in metastasis comparing to primary tumor [39].

Intrinsic $\mathrm{BC}$ subtypes (luminal $\mathrm{A} / \mathrm{B}, \mathrm{HER} 2$ positive, triple negative) have been recognized earlier. IHC measurements of ER, PgR, HER2 and Ki67 serve as surrogate markers to define these subtypes. It may be that intrinsic tumor subtypes better correlate with tumor metabolism than each of these markers separately. In their study, Yoon et al found that FDG PET parameters of primary tumor showed significant differences among the breast cancer subtypes, with a difference in SUVmax between the ER/PgR+,HER2- and ER/PgR-,HER2- [40]. However, we did not find difference in metastatic SUVmax values among different breast cancer subtypes in our patients.

Our study had some limitations. One of the limitations is the absence of histopathological confirmation for the most of the metastases detected on PET/CT. However, we used clinical follow-up to confirm metastatic disease in our patients. Also, in statistical analysis, total number and size of secondary lesions was not taken into consideration, although they varied among the patients noticeably. Another limitation is relatively small sample size. However, to our best knowledge, this is the first study of this kind, which investigates the difference between IDC and ILC metastatic metabolism activity on PET/CT in patients with breast cancer, and also the association of primary tumor grade, ER and PgR status, HER2 and Ki67 expression and tumor subtype with FDG PET/CT metastatic glucose metabolism level, and further studies with larger sample and histopathological confirmation are needed.

In conclusion, SUVmax values detected in breast cancer metastatic lesions (highest SUVmax independently of site, and SUVmax in each regional and distant lymph nodes, bones and liver separately) do not differ between patients with ductal and lobular carcinoma. Our results suggest that glucose metabolism level in breast cancer metastasis is not associated with primary tumor histological type. Also, metabolic activity in breast cancer secondary lesions is not connected with primary tumor characteristics such as histological grade, ER, PgR and HER2 status, Ki67 index and tumor subtype.

Acknowledgements: The study is supported by the Serbian Ministry of Education and Science (Grant numbers 175018,III41031).

\section{References}

[1] TORRE LA, BRAY F, SIEGEL RL, FERLAY J, LORTETTIEULENT J et al. Global cancer statistics, 2012. CA Cancer J Clin 2015; 65: 87-108. http://dx.doi.org/10.3322/caac.21262

[2] LI CI, URIBE DJ AND DALING JR. Clinical characteristics of different histologic types of breast cancer. Br J Cancer 2005; 93: 1046-1052. http://dx.doi.org/10.1038/sj.bjc.6602787

[3] PEROU CM, SURLIE T, EISEN MB, VAN DEN RIJN M, JEFFREYK SS et al. Molecular portraits of human breast tumors. Nature 2000; 406: 747-752. http://dx.doi. org/10.1038/35021093

[4] SKASKO E, PASZKO Z, MAZUR S. A new look at the prognostic value of the estrogen, progesterone and epidermal growth factor receptors in breast cancer tissue. Neoplasma 2005; 52: 10-17.

[5] GOLDHIRSCH A, WINER EP, COATES AS, GELBER RD, PICCART-GEBHART M et al. Personalizing the treatment of women with early breast cancer: highlights of the St Gallen International Expert Consensus on the Primary Therapy of Early Breast Cancer 2013. Ann Oncol 2013; 24: 2206-2223. http://dx.doi.org/10.1093/annonc/mdt303

[6] BOURGEOIS AC, WARREN LA, CHANG TT, EMBRY S, HUDSON K et al. Role of positron emission tomography/computed tomography in breast cancer. Radiol Clin N Am 2013; 51: 781-798. http://dx.doi.org/10.1016/j.rcl.2013.06.003

[7] LEE JH. Radionuclide methods for breast cancer staging. Semin Nucl Med 2013; 43: 294-298. http://dx.doi.org/10.1053/j. semnuclmed.2013.04.001

[8] BROWN RS, WHAL RL. Over expression of Glut-1 glucose transporter in human breast cancer: an immunohistochemical study. Cancer 1993; 72: 2979-2985. http://dx.doi. org/10.1002/1097-0142(19931115)72:10<2979::AIDCNCR2820721020>3.0.CO;2-X

[9] JADVAR H, ALAVI A, GAMBHIR SS. 18F-FDG uptake in lung, breast, and colon cancers: molecular biology correlates and disease characterization. J Nucl Med 2009; 50: 1820-1827. http://dx.doi.org/10.2967/jnumed.108.054098

[10] HEUDEL P, CIMARELLI S, MONTELLA A, BOUTEILLE C, MOGNETTI T. Value of PET-FDG in primary breast cancer based on histopathological and immunohistochemical prognostic factors. Int J Clin Oncol 2010; 15: 588-593. http:// dx.doi.org/10.1007/s10147-010-0120-3

[11] SANLI Y, KUYUMCU S, OZKAN ZG, IŞIK G, KARANLIK $\mathrm{H}$ et al. Increased FDG uptake in breast cancer is associated with prognostic factors. Ann Nucl Med 2012; 26: 345-350. http://dx.doi.org/10.1007/s12149-012-0579-2

[12] EKMEKCIOGLU O, ALIYEV A, YILMAZ S, ARSLAN E, KAYA R et al. Correlation of $18 \mathrm{~F}$-fluorodeoxyglucose uptake with histopathological prognostic factors in breast carcinoma. Nucl Med Commun 2013; 34: 1055-1067. http://dx.doi. org/10.1097/MNM.0b013e3283658369

[13] MIYAKE KK, NAKAMOTO Y, KANAO S, TANAKA S, SUGIE T et al. Journal Club: Diagnostic value of (18)F-FDG $\mathrm{PET} / \mathrm{CT}$ and $\mathrm{MRI}$ in predicting the clinicopathologic subtypes of invasive breast cancer. AJR Am J Roentgenol 2014; 203: 272-279. http://dx.doi.org/10.2214/AJR.13.11971 
[14] JO JE, KIM JY, LEE SH, KIM S, KANG T. Preoperative 18FFDG PET/CT predicts disease-free survival in patients with primary invasive ductal breast cancer. Acta Radiol 2014 Nov 18. [Epub ahead of print].doi: 10.1177/0284185114556929. http://dx.doi.org/10.1177/0284185114556929

[15] ULANER GA, EATON A, MORRIS PG, LILIENSTEIN J, JHAVERI K et al. Prognostic value of quantitative fluorodeoxyglucose measurements in newly diagnosed metastatic breast cancer. Cancer Med 2013; 2: 725-733. http://dx.doi. org/10.1002/cam4.119

[16] MORRIS PG, ULANER GA, EATON A, FAZIO M, JHAVERI $\mathrm{K}$ et al. Standardized uptake value by positron emission tomography/computed tomography as a prognostic variable in metastatic breast cancer. Cancer 2012; 118: 5454-5462. http:// dx.doi.org/10.1002/cncr.27579

[17] ALLRED DC, CARLSON RW, BERRY DA, BURSTEIN HJ, EDGE SB et al. NCCN Task Force Report: Estrogen Receptor and Progesterone Receptor Testing in Breast Cancer by Immunohistochemistry. J Natl Compr Canc Netw 2009; 7: S1-S21; quiz S22-3.

[18] HAMMOND ME, HAYES DF, DOWSETT M, ALLRED DC, HAGERTY KL et al. American Society of Clinical Oncology/ College Of American Pathologists guideline recommendations for immunohistochemical testing of estrogen and progesterone receptors in breast cancer. J Clin Oncol 2010; 28: 2784-2795. Erratum in: J Clin Oncol 2010; 28: 3543. http:// dx.doi.org/10.1200/JCO.2009.25.6529

[19] E.O.R.T.C. Breast Co-operative Group. Revision of the standards for the assessment of hormone receptors in human breast cancer; report of the second E.O.R.T.C. workshop, held on 16-17 March, 1979, in the Netherlands Cancer Institute. Eur J Cancer 1980; 16: 1513-1515. http://dx.doi.org/10.1016/00142964(80)90064-X

[20] WEIGELT B, GEYER FC, REIS-FILHO JS. Histological types of breast cancer: how special are they? Mol Oncol 2010; 4: 192-208. http://dx.doi.org/10.1016/j. molonc.2010.04.004

[21] HARRIS M, HOWELL A, CHRISSOHOU M, SWINDELL RI, HUDSON $\mathrm{M}$ et al. A comparison of the metastatic pattern of infiltrating lobular carcinoma and infiltrating duct carcinoma of the breast. Br J Cancer 1984; 50: 23-30. http:// dx.doi.org/10.1038/bjc.1984.135

[22] BORST MJ, INGOLD JA. Metastatic patterns of invasive lobular versus invasive ductal carcinoma of the breast. Surgery 1993; 114: 637-641; discussion 641-642.

[23] MORENO-SANCHEZ R, RODRIGUEZ-ENRIQUEZ S, MARIN-HERNANDEZ A, SAAVEDRA E. Energy metabolism in tumor cells. FEBS J 2007; 274: 1393-1418. http:// dx.doi.org/10.1111/j.1742-4658.2007.05686.x

[24] KIM YH, JUNG WH, KOO JS. Expression of metabolismrelated proteins in invasive lobular carcinoma: comparison to invasive ductal carcinoma. Tumor Biol 2014; 35: 10381-10393. http://dx.doi.org/10.1007/s13277-014-2345-7

[25] FROLIK D, CADUFF R, VARGA Z. Pleomorphic lobular carcinoma of the breast: its cell kinetics, expression of oncogenes and tumor suppressor genes compared with invasive ductal carcinomas and classical infiltrating lobular carcinomas. Histopathology 2001; 39: 503-513. http://dx.doi. org/10.1046/j.1365-2559.2001.01252.x

[26] CORADINI D, PELLIZZARO C, VENERONI S, VENTURA L, DAIDONE MG. Infiltrating ductal and lobular breast carcinomas are characterised by different interrelationships among markers related to angiogenesis and hormone dependence. Br J Cancer 2002; 87: 1105-1111. http://dx.doi.org/10.1038/ sj.bjc. 6600556

[27] DEANDREIS D, AL GHUZLAN A, LEBOULLEUX S, LACROIX L, GARSI JP et al. Do histological, immunohistochemical, and metabolic (radioiodine and fluorodeoxyglucose uptakes] patterns of metastatic thyroid cancer correlate with patient outcome? Endocr Relat Cancer 2011; 18: 159-169. http://dx.doi.org/10.1677/ERC-10-0233

[28] TAKALKAR AM, EL-HADDAD G, LILIEN DL. FDG-PET and PET/CT - Part II. Indian J Radiol Imaging 2008; 18: 17-36. http://dx.doi.org/10.4103/0971-3026.38504

[29] KIM BS, RYU HS, KANG KH. The value of preoperative PET-CT in papillary thyroid cancer. J Int Med Res 2013; 41: 445-456. http://dx.doi.org/10.1177/0300060513475743

[30] LAHDESMAKI H, HAO X, SUN B, HU L, YLI-HARJA $\mathrm{O}$ et al. Distinguishing key biological pathways between primary breast cancers and their lymph node metastases by gene function-based clustering analysis. Int J Oncol 2004; 24: 1589-1596.

[31] HENNIPMAN A, VAN OIRSCHOT BA, SMITS J, RIJKSEN G, STAAL GE. Glycolytic enzyme activities in breast cancer metastases. Tumor Biol 1988; 9: 241-248. http://dx.doi. org/10.1159/000217568

[32] PALMIERI D, FITZGERALD D, SHREEVE SM, HUA E, BRONDER JL et al. Analyses of Resected Human Brain Metastases of Breast Cancer Reveal the Association between Up-Regulation of Hexokinase 2 and Poor Prognosis. Mol Cancer Res 2009; 7: 1438-1445. http://dx.doi. org/10.1158/1541-7786.MCR-09-0234

[33] KIM HM, JUNG WJ, KOO JS. Site-specific metabolic phenotypes in metastatic breast cancer. J Transl Med 2014; 12: 354. http://dx.doi.org/10.1186/s12967-014-0354-3

[34] PAUDYAL B, ORIUCHI N, PAUDYAL P, HIGUCHI T, NAKAJIMA T et al. Expression of glucose transporters and hexokinase II in cholangiocellular carcinoma compared using [18F]-2-fluro-2-deoxy-D-glucose positron emission tomography. Cancer Sci 2008; 99: 260-266. http://dx.doi. org/10.1111/j.1349-7006.2007.00683.x

[35] JABBOUR MN, MASSAD CY, BOULOS FI. Variability in hormone and growth factor receptor expression in primary versus recurrent, metastatic, and post-neoadjuvant breast carcinoma. Breast Cancer Res Treat 2012; 135: 29-37. http:// dx.doi.org/10.1007/s10549-012-2047-Z

[36] NAKAJO M, KAJIYA Y, KANEKO T, KANEKO Y, TAKASAKI $\mathrm{T}$ et al. FDG PET/CT and diffusion-weighted imaging for breast cancer: prognostic value of maximum standardized uptake values and apparent diffusion coefficient values of the primary lesion. Eur J Nucl Med Mol Imaging 2010; 37: 2011-2020. http://dx.doi.org/10.1007/s00259-010-1529-7

[37] SONG BI, HONG CM, LEE HJ, KANG S, JEONG SY et al. Prognostic Value of Primary Tumor Uptake on F-18 FDG 
PET/CT in Patients with Invasive Ductal Breast Cancer. Nucl Med Mol Imaging 2011; 45: 117-124. http://dx.doi. org/10.1007/s13139-011-0081-0

[38] ZHAO YH, ZHOU M, LIU H, DING Y, KHONG HT et al. Upregulation of lactate dehydrogenase A by ErbB2 through heat shock factor 1 promotes breast cancer cell glycolysis and growth. Oncogene 2009; 28: 3689-3701. http://dx.doi. org/10.1038/onc.2009.229

[39] IBRAHIM T, FAROLFI A, SCARPI E, MERCATALI L, MEDRI L et al. Hormonal receptor, human epider- mal growth factor receptor-2, and Ki67 discordance between primary breast cancer and paired metastases: clinical impact. Oncology 2013; 84: 150-157. http://dx.doi. org/10.1159/000345795

[40] YOON HJ, KANG KW, CHUN IK, CHO N, IM SA et al. Correlation of breast cancer subtypes, based on estrogen receptor, progesterone receptor, and HER2, with functional imaging parameters from ${ }^{68} \mathrm{Ga}-\mathrm{RGD} \mathrm{PET} / \mathrm{CT}$ and ${ }^{18} \mathrm{~F}-\mathrm{FDG}$ PET/CT. Eur J Nucl Med Mol Imaging 2014; 41: 1534-1543. http://dx.doi.org/10.1007/s00259-014-2744-4 